\title{
The Choice of Journey Destinations and Lengths of Stay: A Micro Analysis ${ }^{\dagger}$
}

\author{
James Mak \\ and \\ James E. T. Moncur*
}

Since the 1960's, there has been growing awareness of the importance of pleasure travel as a component of interregional trade and moreover, that travel has become increasingly multi-destinational. Recent increases in airfares have altered the relative costs of travel and intensified competition among vying destinations. How best to maintain one's relative market position depends on an awareness of the determinants of visitor flows. Despite this, there exists little theoretical or empirical research on the individual demand for travel. Only the study by Rugg (1973) attempts a rigorous analysis of these determinants.

Using Lancaster's (1966) approach to consumer theory, Rugg develops a model of consumer choice capable of simultaneously determining the traveler's choices of journey destinations and journey duration. Briefly, Rugg alleges that a consumer's choice of trip destinations and lengths of stay depend on the attributes of individual destinations in addition to the usual economic variables found in conventional travel demand models. According to Rugg (p. $65)$ :

A traveler does not derive utility from possessing or consuming travel destinations, rather, the traveler derives utility from being in the particular destination for some period of time. Dwelling in the destination allows the traveler to consume destinational attributes or characteristics, such as a pleasant climate or beautiful scenery, from which the traveler may then derive utility. Goods are therefore defined to be an individual's being or dwelling at the place of destination for a unit period of time.

Given budget and time constraints and his preference function for destinational characteristics, an individual maximizes utility by purchasing "goods" (i.e., spending days in destinations) that produce the desired bundle of these characteristics.

\footnotetext{
tWe are indebted to E. Fujii, M. Ghali, A. Mason, W. Miklius, M. Snow, and an anonymous referee for helpful comments.
}

* University of Hawaii, Honolulu, HA. 
Unfortunately, Rugg's empirical model fails to provide an adequate test of his theory. The dependent variable in his model is not the number of days spent visiting each destination, as required by theory, but the total number of scheduled airline passengers traveling in both directions between each pair of nine European countries. ${ }^{1}$ At best, his model can provide only a test of the travelers' choices of journey destinations but not of their duration. Also, the use of aggregate travel flow data precludes the inclusion of individual traveler characteristics in the model specification, thereby further diluting the test by obscuring differences in individual preference functions.

In this paper, we propose an alternative specification, a Tobit model, ${ }^{2}$ capable of simultaneously determining the traveler's probable choice of destinations as well as the expected length of stay in each destination. The model is tested using micro data obtained by the Hawaii Visitors Bureau in a year-long survey of U.S. mainland visitors to Hawaii in $1974 .{ }^{3}$ Hawaii consists of four separate island destinations. On average, each tourist visits two destinations per trip.

\section{THE MODEL}

The appropriate specification of the travel choice model is:

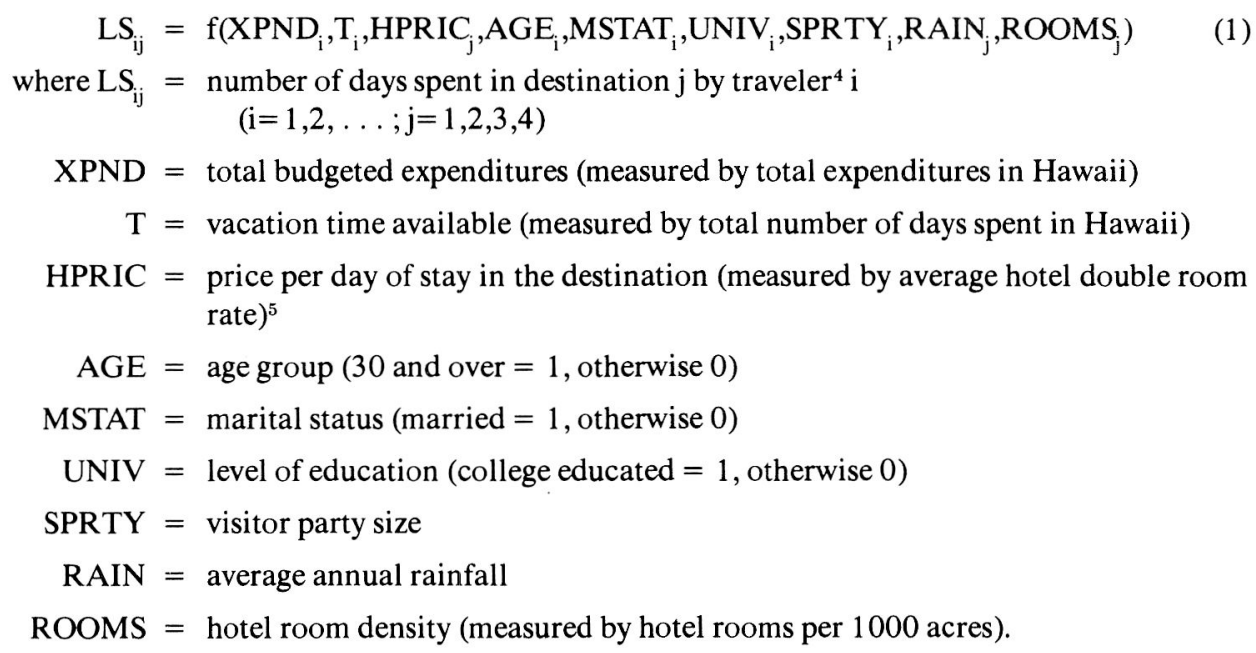

The dependent variable, $\mathrm{LS}_{\mathrm{ij}}$, measures the length of stay (in days) by traveler $\mathrm{i}$ in destination $\mathrm{j}$. $\mathrm{LS}_{\mathrm{ij}}=0$ if traveler $\mathrm{i}$ does not visit destination $\mathrm{j}$. The variables XPND and $T$ are proxies for budget and time constraints, respectively, as direct observations are unavailable. HPRIC is a proxy variable for the price of a day's stay at the destination. The variables AGE ${ }^{6}$, MSTAT, and UNIV describe personal characteristics of the traveler and control for differences in individual preferences. SPRTY tests whether additional party members, such as spouse and children, accompanying the traveler influence his choice of journey destinations and duration. ${ }^{7}$ 
The variables RAIN and ROOMS describe destinational characteristics. The assumption is that differences in rainfall (climate) and in the density of resort development adequately characterize the differences in recreational experience the four destinations have to offer. We paid particular attention to the choice of variables to describe the destinational attributes. Since travel to Hawaii is principally "sunlust" rather that "wanderlust" travel (Gray, 1970), we believe that climate (RAIN) is an important variable in the traveler's choice of destinations and lengths of stay. ${ }^{8}$ Sunlust travel is also characterized as either being relaxing and restful or very active, rather than educational and informative. Hence, the variable ROOMS (hotel room density) is also included to capture the relative differences in the recreational activity level offered by the four destinations. The assumption is that a densely developed resort is likely to offer a more active recreational experience than a sparsely developed one. ${ }^{9}$

Note that both travel times and airfares (travel cost) to and between destinations have been excluded from the model specification due to the lack of information on actual travel times and fares paid by individual visitors. However, this may not be a serious shortcoming. For a given individual visiting Hawaii, travel costs and travel times to any of the four destinations are roughly the same. And, under Common Fare regulations, travel costs between any pair of destinations within Hawaii are the same, while differences in travel times between destinations are negligible. ${ }^{10}$ Accordingly, XPND and $\mathrm{T}$ in equation (1) are net of travel costs and travel times, respectively.

In this model, we expect that the signs of the coefficients of XPND and T are positive, negative signs are expected for the coefficients of HPRIC and RAIN, and we have no prior expectations with respect to the signs of the coefficients of the remaining variables.

While there are a number of functional forms available to estimate equation (1), our choice is constrained by the presence in the sample of a large number of observations on the dependent variable at the lower limit of zero days. Visitors to Hawaii typically do not visit all four destinations. Since models with truncated distribution of the dependent variables violate the usual assumptions underlying the desirable properties of the ordinary least squares regression method, we have to use alternative estimation techniques.

An appropriate one-step procedure is the Tobit model, first developed by Tobin (1958) to estimate the probability and the extent of household purchases of consumer durables. A detailed explanation of Tobit analysis is contained in the Appendix.

Unfortunately, there does not exist a computational program for Tobit that permits multiple dependent variables. Recall that our model contains four dependent variables $\left(L S_{i j}, j=1,2,3,4\right)$, since each visitor chooses among four destinations. To make this problem empirically tractable, we use a random number generating procedure to select one dependent variable for each visitor. Specifically, each destination is assigned an interval between zero and one as follows: 


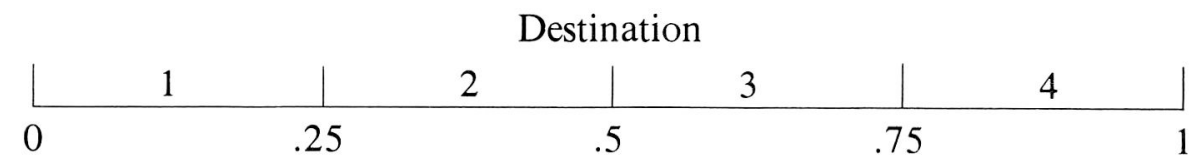

A random number, between zero and one, is then generated from a uniform distribution for each visitor in the sample. If, for example, the number generated is .6 , then the dependent variable for visitor $\mathrm{i}\left(\mathrm{LS}_{\mathrm{ij}}\right)$ takes the value in Destination 3. If visitor i did not visit Destination 3, then $\mathrm{LS}_{\mathrm{i} 3}=0 .{ }^{11}$

\section{THE RESULTS}

As noted earlier, the data to estimate equation (1) consist of survey responses from 1,892 U.S. mainland visitor parties to Hawaii. We partition the entire sample into two subsamples, first time visitors and repeat visitors, and estimate equation (1) separately over each subsample. Hawaii Visitors Bureau data suggest that first time and repeat visitors behave differently (Richardson and Donehower, 1976). To test if these two sets of regressions are equivalent (i.e., have the same intercept and slopes), we estimate equation (2) using Tobit procedures with pooled data from both subsamples. The model, with subscripts deleted, becomes:

$$
\begin{aligned}
\mathrm{LS}= & \mathrm{f}^{\prime}(\text { XPND,T,HPRIC,AGE,MSTAT,UNIV,SPRTY,RAIN, } \\
& \text { ROOMS,D,XPNDD,TD,HPRICD,AGED,MSTATD, } \\
& \text { UNIV,SPRTYD,RAIND,ROOMSD) }
\end{aligned}
$$

where $\mathrm{D}$ denotes a dummy variable with the value of one for a repeat visitor and zero for a first time visitor, and the variables XPNDD,TD, ..., ROOMSD represent the product of $\mathrm{D}$ and the corresponding regressor. The general procedure is described by Johnston (1972, pp. 194-206), and Snow

\begin{tabular}{|c|c|c|c|c|c|c|c|c|c|c|}
\hline & LS & XPND & $\mathrm{T}$ & HPRIC & $\mathrm{AGE}$ & MSTAT & UNIV & SPRTY & RAIN & ROOMS \\
\hline LS & 1.000 & & & & & & & & & \\
\hline XPND & .150 & 1.000 & & & & & & & & \\
\hline $\mathrm{T}$ & .290 & .469 & 1.000 & & & & & & & \\
\hline HPRIC & -.086 & -.013 & -.015 & 1.000 & & & & & & \\
\hline AGE & .004 & .119 & .180 & .022 & 1.000 & & & & & \\
\hline MSTAT & -.005 & .061 & -.006 & -.007 & .201 & 1.000 & & & & \\
\hline UNIV & .070 & .124 & .083 & -.009 & -.057 & .019 & 1.000 & & & \\
\hline SPRTY & .039 & .064 & .000 & .003 & .147 & .466 & .062 & 1.000 & & \\
\hline RAIN & -.307 & -.002 & -.019 & -.348 & -.034 & -.456 & -.019 & -.025 & 1.000 & \\
\hline ROOMS & .558 & -.002 & .011 & -.064 & -.008 & .018 & .058 & .031 & -.456 & 1.000 \\
\hline Mean & 2.78 & 443.47 & 11.19 & 27.61 & .77 & .77 & .51 & 1.92 & 38.11 & 21.75 \\
\hline Std dev & 3.90 & 270.92 & 5.21 & 2.76 & .42 & .42 & .50 & .89 & 17.55 & 26.26 \\
\hline
\end{tabular}

TABLE 1

Correlation Matrix and Summary Statistics

$n=1892$. 
(1978) has shown its equivalence to the familiar Chow test used in tests of sets of linear regressions. The two regressions are equivalent if the coefficients of the $\mathrm{k}+1$ variables $\mathrm{D}, \mathrm{XPNDD}, \mathrm{TD}, \ldots, \mathrm{ROOMSD}$ in equation (2) are zero.

Table 1 displays the correlation matrix and summary statistics of the variables in equation (1) for both first time and repeat visitors combined. Table 2 shows estimated coefficients of the Tobit index function $\mathrm{I}=\mathrm{X} \beta$ (see Appendix). Results for the 998 first time and 894 repeat visitor parties appear separately. Likelihood ratio tests allow us to reject the hypotheses $\beta_{1}=\beta_{2}=$ $\ldots=\beta_{\mathrm{k}}=0$ for both subsamples. Significant coefficients $\left(\chi_{1}^{2}\right.$ statistic at 0.10 level) are indicated by ${ }^{*}$. Table 2 also presents the computed elasticities of $E\left(\mathrm{LS}_{\mathrm{ij}}\right)$ at mean values of the regressors.

TABLE 2

Estimated Coefficients

(Dependent variable is $\mathrm{LS}_{\mathrm{ij}}$ )

\begin{tabular}{|c|c|c|c|c|c|c|}
\hline \multirow[b]{2}{*}{$\begin{array}{c}\text { Variable } \\
\text { Name }\end{array}$} & \multicolumn{3}{|c|}{ First Time Visitors } & \multicolumn{3}{|c|}{ Repeat Visitors } \\
\hline & $\begin{array}{l}\text { Coefficient } \\
\text { (Std error) } \\
\end{array}$ & $-2(\ln \lambda)$ & $\begin{array}{c}\text { Elasticity of } \\
\text { E(LS) at } \\
\text { means } \\
\end{array}$ & $\begin{array}{l}\text { Coefficient } \\
\text { (Std error) } \\
\end{array}$ & $-2(\ln \lambda)$ & $\begin{array}{c}\text { Elasticity of } \\
E(L S) \text { at } \\
\text { means }\end{array}$ \\
\hline XPND & $\begin{array}{l}.00125^{*} \\
(.00062)\end{array}$ & 4.065 & .15197 & $\begin{array}{l}.00159^{*} \\
(.00076)\end{array}$ & 4.320 & .17183 \\
\hline $\mathrm{T}$ & $\begin{array}{l}.35073^{*} \\
(.03281)\end{array}$ & 113.645 & 1.0666 & $\begin{array}{l}.29709^{*} \\
(.04050)\end{array}$ & 53.165 & .81883 \\
\hline HPRIC & $\begin{array}{c}-.12600^{*} \\
(.0595)\end{array}$ & 4.506 & -.98843 & $\begin{array}{c}-.32485^{*} \\
(.8786)\end{array}$ & 14.719 & -2.10860 \\
\hline AGE & $\begin{array}{c}-.81146^{*} \\
(.32377)\end{array}$ & 6.266 & -.16523 & $\begin{array}{l}-.29888 \\
(.56870)\end{array}$ & .222 & -.05797 \\
\hline MSTAT & $\begin{array}{l}-.05131 \\
(.38758)\end{array}$ & .017 & -.01139 & $\begin{array}{r}-.26249 \\
(.54900)\end{array}$ & .276 & -.04691 \\
\hline UNIV & $\begin{array}{c}.16738 \\
(.27998)\end{array}$ & .357 & .02450 & $\begin{array}{c}.41985 \\
(.40839)\end{array}$ & 1.057 & .04899 \\
\hline SPRTY & $\begin{array}{l}.21107 \\
(.17811)\end{array}$ & 1.399 & .11553 & $\begin{array}{l}.61398^{*} \\
(.25439)\end{array}$ & 5.805 & .27478 \\
\hline RAIN & $\begin{array}{c}-.04145^{*} \\
(.01022)\end{array}$ & 16.387 & -.44940 & $\begin{array}{c}-.05314^{*} \\
(.01446)\end{array}$ & 13.442 & -.47529 \\
\hline ROOMS & $\begin{array}{l}.11419^{*} \\
(.00627)\end{array}$ & 339.414 & .73402 & $\begin{array}{l}.11590^{*} \\
(.00876)\end{array}$ & 117.369 & .56562 \\
\hline INTERCEPT & $\begin{array}{c}-.60449 \\
(1.95868)\end{array}$ & - & - & $\begin{array}{c}3.55950 \\
(2.84609)\end{array}$ & - & - \\
\hline$\hat{\sigma}$ & & 3.8759 & - & & 5.2809 & - \\
\hline $\begin{array}{c}-2(\ln \lambda) \\
n\end{array}$ & & $\begin{array}{c}659.0104 \\
998\end{array}$ & - & & $\begin{array}{c}386.0114 \\
894\end{array}$ & - \\
\hline
\end{tabular}

Note: Significant coefficients are indicated by an * 
We also estimated equation (2) (results not shown). ${ }^{12}$ Likelihood ratio tests of the individual coefficients indicate that only the coefficients of TD and HPRICD among the variables D,XPND,...,ROOMSD are significantly different from zero. ${ }^{13}$

The results reported in Table 2 agree with our prior expectations. In both regressions, the coefficients of the budget (XPND) and time (T) constraints have positive signs. The magnitudes of their respective partial elasticities (at mean values of the regressors) also seem reasonable, between .82 and 1.06 for the time constraint but much smaller (.15 to .17) for the budget constraint. The modest size of the latter suggests that, given the number of vacation days available and given also the attributes of the alternative destinations, a traveler with a larger budget is unlikely to visit many more destinations or stay much longer at each destination; rather, he is likely to purchase a higher quality (i.e., more expensive) vacation.

The coefficient of the price variable, HPRIC, is negative and significantly different from zero in both equations, indicating that consumers' choices of journey destinations and lengths of stay are sensitive to destination prices. Higher prices in one destination may result in either a change of destination or a reduction in time spent in the preferred destination. Not surprisingly, first time visitors are much less sensitive to price variations $(\epsilon=-0.99)$ than repeat visitors $(\epsilon=-2.11)$.

Among the variables describing personal characteristics, only AGE is important in influencing travel choice, but solely for first time visitors. By contrast, the size of the visitor party is a significant determinant of travel choice only for repeat visitors. We are unable to provide a common sense explanation for these results.

The destinational characteristics variables RAIN and ROOMS (different from zero in both regressions) comprise the core of the travel choice model. As expected, rain deters tourists. By contrast, (Hawaii) visitors generally prefer to vacation in highly developed to sparsely developed resort areas. These results support Rugg's notion that consumers derive utility from characteristics produced by commodities, at least if the commodity is travel.

One concern remains. Since we have no direct observations on each visitor's budget and time constraints, the results in Table 2 assume that actual expenditures and total number of days spent in Hawaii are appropriate proxies, although, more precisely, they are equilibrium values rather than constraints. To determine how sensitive our results are to the choice of proxies for these two constraints, we experiment with another pair of proxies. We replace total expenditures (XPND) with income $(\mathrm{Y})^{14}$ as the alternative proxy for the budget constraint.

Choosing an alternative proxy for the time constraint poses a more difficult problem. An examination of the frequency distribution of visitor lengths of stay reveals that the frequencies exhibit a bimodal distribution, the modes being 8 and 15 days. Since a visitor with one week's vacation can stay in Hawaii 9 days, at most, and one with two week's vacation can stay up to 16 
TABLE 3

Estimated Coefficients for the Income and Vacation Days Variables

(Dependent variable is $\mathrm{LS}_{\mathrm{ij}}$ )

\begin{tabular}{|c|c|c|c|c|c|c|}
\hline \multirow[b]{2}{*}{$\begin{array}{c}\text { Variable } \\
\text { Name } \\
\end{array}$} & \multicolumn{3}{|c|}{ First Time Visitors } & \multicolumn{3}{|c|}{ Repeat Visitors } \\
\hline & $\begin{array}{l}\text { Coefficient } \\
\text { (Std error) }\end{array}$ & $-2(\ln \lambda)$ & $\begin{array}{c}\text { Elasticity of } \\
E(L S) \text { at } \\
\text { means }\end{array}$ & $\begin{array}{c}\text { Coefficient } \\
\text { (Std error) } \\
\end{array}$ & $-2(\ln \lambda)$ & $\begin{array}{c}\text { Elasticity of } \\
\text { E(LS) at } \\
\text { means }\end{array}$ \\
\hline $\mathrm{Y}$ & $\begin{array}{l}.00150 \\
(.02422)\end{array}$ & .00383 & .00849 & $\begin{array}{l}.05852 \\
(.03751)\end{array}$ & 2.43364 & .28531 \\
\hline VAC & $\begin{array}{c}.28909^{*} \\
(.02936)\end{array}$ & 96.92599 & 1.09050 & $\begin{array}{c}.37260^{*} \\
(.04181)\end{array}$ & 79.40917 & 1.20920 \\
\hline
\end{tabular}

Note: Significant coefficients are indicated by an ${ }^{*}$.

days, the modes correspond well to one week and two week vacation days available. Hence, for all visitors who stay 9 days or less, we assign as the alternative proxy for the time constraint, $\mathrm{VAC}=9$. For those who stay more than 9 days but less than 17 days, we assign $\mathrm{VAC}=16$. Finally, for those who remain for 17 days or longer, we assign $\mathrm{VAC}=$ actual length of stay. About $5 \%$ of the visitors stay 17 days or longer.

We re-estimate equation (1) with the alternative proxies for budget (Y) and time (VAC) constraints. Not surprisingly, the results indicate a slight deterioration in the overall "fit". ${ }^{15}$ The regression coefficients for Y and VAC are displayed in Table 3 and are similar to those in Table 2 for their comparable variables. They confirm the earlier findings that, all else being equal, visitors to Hawaii attach greater importance to the amount of available vacation time, rather than money, in determining their choice of destinations and their lengths of stay in each. The coefficients of the remaining variables (not shown) remain generally the same as those in Table 2 . In short, our results are not particularly sensitive to the choice of proxies for the budget and time constraints.

Finally, to illustrate the results in Table 2, we compare four representative tourists (A-D) who have the same personal characteristics but differ in the amounts of money and vacation days available and in trip number (first time vs. repeat). The probability of each individual visiting each of the four destinations and the expected number of days spent in each destination are given in Table 4. These comparisons indicate that, all else being equal, the amount of vacation time available is more important in determining destination choices and trip duration (B vs. C) than the size of the travel budget (A vs. B) or trip number ( $C$ vs. D). Also, for each individual, the large differences in the probability of visiting each destination and in lengths of stay illustrate the importance of destinational attributes and relative prices in influencing travel choices. 
TABLE 4

Probability of Visiting Alternative Destinations and Expected Lengths of Stay

\begin{tabular}{|c|c|c|c|c|}
\hline & A & $\mathrm{B}$ & $\mathrm{C}$ & $\mathrm{D}$ \\
\hline & $\begin{array}{l}\mathrm{Y}=\$ 450 \\
\mathrm{~T}=9 \text { days } \\
\text { First Time }\end{array}$ & $\begin{array}{l}\mathrm{Y}=\$ 750 \\
\mathrm{~T}=9 \text { days } \\
\text { First Time }\end{array}$ & $\begin{array}{l}Y=750 \\
T=15 \text { days } \\
\text { First Time }\end{array}$ & $\begin{array}{l}\mathrm{Y}=750 \\
\mathrm{~T}=15 \text { days } \\
\text { Repeat }\end{array}$ \\
\hline \multicolumn{5}{|c|}{ Probability of Visit } \\
\hline \multicolumn{5}{|c|}{ Destination } \\
\hline 1 & .30 & .33 & .54 & .40 \\
\hline 2 & .93 & .94 & .98 & .93 \\
\hline 3 & .46 & .49 & .70 & .60 \\
\hline 4 & .25 & .28 & .49 & .45 \\
\hline \multicolumn{5}{|c|}{ Expected Length of Stay (days) } \\
\hline 1 & .7 & .9 & 1.8 & 1.5 \\
\hline 2 & 5.9 & 6.3 & 8.3 & 7.9 \\
\hline 3 & 1.3 & 1.5 & 2.8 & 2.8 \\
\hline 4 & 6 & .9 & 1.5 & 1.8 \\
\hline
\end{tabular}

Note: The tourists depicted in Table 2 are over 30 years old, married,. college graduates, and traveling in parties of two.

\section{CONCLUSION}

In this paper we proposed a Tobit model capable of simultaneously determining a traveler's choice of journey destinations and duration. The model includes as explanatory variables the descriptive characteristics of individual destinations in addition to the usual economic variables found in conventional travel demand models. The model was tested using micro data from Hawaii. Our results confirm the hypothesis that consumers' choices of journey destinations and duration are indeed influenced by destinational attributes in addition to relative price differences among destinations and the amount of money and time available. We also found that, once travelers decide to visit Hawaii, the amount of available vacation time is more important than the size of the travel budget in determining their choice of Hawaiian destinations and the lengths of stay in each. We suspect that this might also be true of travel to Europe, the Caribbean, or other tourist regions where multi-destinational travel prevails. Finally, our results indicate that repeat visitors are more sensitive to price variations than first time visitors to a region.

\section{FOOTNOTES}

1 Thus his sample consists of ${ }_{9} \mathrm{C}_{2}=36$ observations on aggregate travel flows. Clearly, the lack of appropriate data explains his inability to perform tests of his theory.

2 See Tobin (1958); also, Goldberger (1964).
3 The entire sample consists of 6,000 observations on U.S. visitor parties. We deleted all those who were on business trips or on package tours. The latter were deleted because their destination choices and trip durations are in- 
stitutionally, and not individually, determined. The remaining sample of 1,892 observations consists of independent (FIT) travelers on pleasure trips.

4 Actually, the relevant decision making unit is the tourist party rather than the individual tourist. This problem can be overcome by assuming party size $=1$, without loss of generality.

The destination choice set is limited by available data to the four island destinations in Hawaii. The model does not consider the traveler's decision to visit Hawaii vis-a-vis some other destination(s) such as Europe, the Caribbean, other tropical islands in the Pacific, etc. In principal, the model can be extended to consider the larger choice sets.

5 These are average double room rates (weighted by the number of rooms at each rate) for a representative sample of hotels selected by the Hawaii Visitors Bureau.

6 Age is treated as a dichotomous variable to test for intergeneration differences in taste.

7 Surveys of husbands and wives indicate that the choice of destinations is typically a joint decision. (See Travel Research International, 1968).

8 Each year the Hawaii Visitors Bureau surveys U.S. visitors to Hawaii to solicit their (quality) ratings of tourist facilities in Hawaii. The ratings range from poor (1) to excellent (5). Results clearly indicate that some islands are perceived to have better beaches than other islands. Such impressions are no doubt made known to potential travelers by travel agents or through friends. Thus, an alternative specification of equation (1), consistent with sunlust travel, replaces the RAIN variable with a $\mathrm{BEACH}$ quality variable. The simple correlation between the two variables is $r=$ -.92 . Our estimates show that the coefficient of $\mathrm{BEACH}$ is positive and significant, as expected. Both specifications yield the same goodness of fit.

9 Clawson and Knetsch (1966) suggest that the satisfaction per user of a region is related to the type of use and the number of users per unit of area. The ROOMS variable accurately measures "density" only if hotels are uniformly dispersed over each of the islands. In fact, hotels are concentrated in resort areas. Our own observations are that the density variable is highly correlated with actual densities.

10 Only two of the four islands are directly accessible by scheduled overseas airlines. The other islands are reached via interisland air carriers upon arrival in Hawaii. Under Common Fare regulations in effect, the additional fare between any pair of destinations would have been $\$ 9$, a negligible sum compared to the round trip coach fare to Hawaii of $\$ 253$ from San Francisco and of $\$ 518$ from New York. While most travelers remain to visit their gateway destination, many transfer directly to other islands, bypassing the gateway destination.

11 This procedure assumes that each destination has the same chance of being selected by tourists. One might argue to the contrary since data indicate that some islands receive a disproportionate number of visitors. For example, about $95 \%$ of the FIT tourists visit Destination 2 while only one-third of them visit Destination 4. (Both are gateway islands.) (Richardson and Donehower, 1978, p. 4) To demonstrate that the choice of a uniform probability distribution has no significant impact on our empirical results, we changed the probability distribution by assigning new (weighted) intervals to the individual destinations, as follows:

\begin{tabular}{|c|c|c|c|c|c|c|}
\hline \multicolumn{7}{|c|}{ Destination } \\
\hline & & 2 & 1 & 3 & 1 & 4 \\
\hline 0 & & & .61 & & .85 & 1.00 \\
\hline
\end{tabular}

The lengths of the intervals were calculated by taking the ratio of actual visitor arrivals in each destination to the sum of visitor arrivals in all four destinations; i.e., Visitor $\mathrm{j}_{\mathrm{j}} / \mathrm{j}_{\mathrm{j}=1}^{4}$

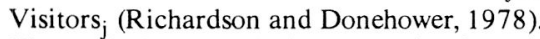
The result, for example, is that Destination 2 is three times as likely to be selected as Destination 4. Fortunately, the results obtained were similar to those from the unweighted distribution.

12 These results may be obtained from the authors upon request.

13 However, similar tests at the 0.1 level do not allow us to reject the null hypothesis that the coefficients of all of the $k+1$ variables, D,XPNDD , . . ROOMSD simultaneously are significantly different from zero. (It can be rejected at the 0.3 level.) The seeming inconsistency between tests of individual coefficients and tests between sets of regressions is apparently not uncommon in the dummy variables technique. We feel that the tests of the individual coefficients are more informative.

14 Incomes are reported as income-ranges. We used the mid-points of these ranges as $\mathrm{Y}$ in Table 3 .

15 The $\mathrm{R}^{2}$ between the predicted and actual values in the original specification are .39 and .48 for repeat and first time visitors respectively; the corresponding ratios in the alternative specification are .38 and .47 . 


\section{REFERENCES}

CLAWSON, MARION AND J. L. KNETSCH. The Economics of Outdoor Recreation. Baltimore: Johns Hopkins Press, 1966.

DEPARTMENT OF PLANNING AND ECONOMIC DEVELOPMENT. State of Hawaii Data Book, 1978. Honolulu, 1978.

GOLDBERGER, ARNOLD. Econometric Theory. New York: John Wiley \& Sons, 1964.

GRAY, H. P. International Travel-International Trade. Lexington: D. C. Heath and Co., 1970.

JOHNSTON, J. Econometric Methods. 2nd ed. New York: McGraw-Hill, 1972.

LANCASTER, KELVIN J., "A New Approach to Consumer Theory," Journal of Political Economy, LXXXIV: 132-157 (1966).

RICHARDSON, EVELYN AND DONEHOWER, ERNEST J., "Characteristics of Repeat and First Time Visitors, 1974," Honolulu: Hawaii Visitors Bureau, (1976).

, "Characteristics of 'Group' and 'FIT' Visitors, 1976," Honolulu: Hawaii Visitors Bureau, (1978).
RUGG, DONALD, "The Choice of Journey Destination: A Theoretical and Empirical Analysis," Review of Economics and Statistics, L: 64-72, (1973).

SNOW, MARCELLUS, "A Note on Dummy Variables and the Chow Test." Honolulu: MS University of Hawaii, 1978.

TOBIN, JAMES, "Estimation of Relationships for Limited Dependent Variables," Econometrica, XXVI: 24-36, 1958.

TRAVEL RESEARCH INTERNATIONAL. The Role of the Husband and Wife in Decisions Involving Pleasure Air Trips. New York, 1968.

UNIVERSITY OF HAWAII PRESS. Atlas of Hawaii. Honolulu, 1973.

WHITE, KENNETH J., "A General Computer Program for Econometric MethodsSHAZAM," Econometrica, XLVI: 239-240, 1978. 


\section{APPENDIX}

Estimation of Tobit Models

The procedure is to estimate an index $\mathrm{I}_{\mathrm{ij}}$ which is a linear function of the regressors so that $\mathrm{I}_{\mathrm{ij}}=\mathrm{X} \beta$. Each observation of the dependent variables $\mathrm{LS}_{\mathrm{ij}}$ is a function of the $X^{\prime}$ 's via $I_{i j}$ and a critical value of the index I* which is distributed $\mathrm{N}\left(0, \sigma^{2}\right)$. The dependent variable then takes the value of the lower limit (zero) whenever $\mathrm{I}_{\mathrm{ij}}$ falls below the critical limit $\mathrm{I}^{*}$, and is the difference between $\mathrm{I}_{\mathrm{ij}}$ and $\mathrm{I}^{*}$ when the index exceeds the critical limit:

$$
\operatorname{LS}_{\mathrm{ij}}=\left\{\begin{array}{ccc}
0 & \text { if } & \mathrm{I}_{\mathrm{ij}}<\mathrm{I}^{*} \\
\mathrm{I}_{\mathrm{ij}}-\mathrm{I}^{*} & \text { if } & \mathrm{I}_{\mathrm{ij}} \geq \mathrm{I}^{*}
\end{array}\right\}
$$

The random variable $\mathrm{I}^{*}$ thus plays the role of a disturbance. For any observation, the probability that the dependent variable exceeds the limit can be found by transforming the calculated value of the index, $\hat{\mathrm{I}}$, (which is unbounded) through the cumulative normal distribution into a variable with range $(0,1)$. If the lower limit is zero, then the expected value of the dependent variable given the values of the $X$ 's is:

$$
E\left(L_{i j} \mid I_{i j}\right)=E\left(L S_{i j} \mid X \beta\right)=I_{i j} F\left(\frac{I_{i j}}{\sigma}\right)+f\left(\frac{I_{i j}}{\sigma}\right)
$$

where $\mathrm{F}$ is the cumulative normal distribution, $\mathrm{f}$ the normal density function, and $\sigma$ the standard error of the estimate. Since the maximum likelihood estimates of the $\beta$ 's are nonlinear in the X's as well as the LS's, the standard OLS computational routines must be replaced by a search procedure. The inverse of the matrix of second derivatives of the likelihood function yields asymptotic standard errors. The statistic $-2(\ln \lambda)$, where $\lambda$ is the likelihood ratio, is distributed approximately $\chi^{2}$ (with $\mathrm{k}$ degrees of freedom) and serves to test $\beta_{1}=\beta_{2}=\ldots=\beta_{k}=0$. Tests of hypotheses on individual parameters can also be performed using the likelihood ratio test. 